\title{
Correspondence
}

\section{Is medical abdicationism widespread?}

\section{DeAr Sir}

The Sunday Times for 6 December 1981 carried a story about a patient who died in a psychiatric hospital after having been given a succession of psychotropic drugs by night nurses. The drugs had been prescribed to be given 'p.r.n.'

The senior consultant at the hospital is said to have told the newspaper: 'We do not know the qualifications of the staff. It is not for the doctor to comment on what is a nursing administration matter.'

I write to ask whether this degree of medical abdicationism is widespread? How does it square with the College's policy on the responsibility of consultants?- - or with a well-integrated multidisciplinary administration? Is it only at Rampton that medical leadership is needed?

I am sure that the Editors and many of the readers of the Bulletin would welcome further correspondence on the subject.

Alexander WalK

\section{Criminal Welfare on Trial}

DeAR SIR

When Can Social Work Survive? was published, June Lait and I took the view that it would be unseemly to reply to every unfriendly review, although in the event most of the reviews-including your own-were quite favourable. I have a similar attitude to my contribution to Criminal Welfare on Trial, but your reviewer has so absurdly misrepresented some of my arguments that I feel I must reply.

The title of my essay was 'Compulsory therapy for crime: bad habits are not diseases'. Dr Bowden seems to think that I am in favour of compulsory therapy ('the goal is totalitarian ...) although, in common with the other three contributors, I am rather opposed to the idea. May I quote one short passage? 'Whether 'treatments' such as female hormones or castration are acceptable is a matter for society, through its elected representatives, to decide ... As with most ethical issues, it is in the end a matter of taste. My own view is that such treatments should never be forced on a sex offender, but that if he would otherwise have to spend many years in prison, it is permissible to offer them as an alternative which might permit him to be at liberty. I should add that I am, on balance, opposed to capital punishment' (italics in original). I cannot understand why Dr Bowden is so shocked by my suggestion of 'some kind of benevolent gulag' for recidivists who are, as I put it, 'a nuisance rather than a menace'. The large psychiatric hospitals used to provide just such a 'gulag' for many of these offenders who now languish in prison despite the fact that some of them are frankly schizophrenic. Does Dr Bowden think the present arrangements an improvement on the old in this respect?

Neither can I understand his amazement at the suggestion that probation officers should administer Antabuse to those convicted of drink-related offences. If he will refer to the study by Bourne et al, ${ }^{1}$ he will see that it is perfectly practicable, and quite often helpful-sometimes spectacularly so. It is certainly more humane than prison, probably more effective than detoxification centres, ${ }^{2}$ and much cheaper than either. It is also much less dangerous than the sort of drinking in which habitual drunken offenders commonly engage when they leave custody.

COLIN BREWER

14 a Abercorn Place

London NW8

\section{REPERENCES}

'Bourne, P. G., Alford, J. A. \& Bowcock, J. Z. (1966) Treatment of skid-row alcoholics with disulfiram. Quarterly Journal of Studies on Alcohol, 27, 42-48.

${ }^{2}$ HAMiLton, J. R. (1979) Evaluation of a detoxification service for habitual drunken offenders. British Journal of Psychiatry. 135, 28-34.

\section{Yorkshire Regional Committee of Consultant Psychiatrists (Mental Handicap)}

\section{Dear Sir}

The consultant psychiatrists working in mental handicap in the Yorkshire Region have formed a committee to discuss matters of mutual interest and to forge closer links with the established bodies.

The Committee would be pleased to hear from similar organizations in other parts of the country.

D. A. SPENCER Secretary to the Committee

Meanwood Park Hospital

Leeds 